\begin{tabular}{|c|c|}
\hline Postprint Version & 1.0 \\
\hline Journal website & $\begin{array}{l}\text { http://www.ingentaconnect.com/content/maney/mmh/2011/00000004/00000004 } \\
\text { /art00006 }\end{array}$ \\
\hline Pubmed link & \\
\hline DOI & 10.1179/1753304X11Y.0000000013 \\
\hline
\end{tabular}

This is a NIVEL certified Post Print, more info at http://www.nivel.eu

\title{
The growth and decline of health community centres in the Netherlands: A macro-historical Analysis.
}

\author{
RONALD BATENBURG ${ }^{1}$, ARTHUR EYCK ${ }^{2}$. \\ ${ }^{1}$ The Netherlands Institute of Health Services Research, 3500 BN Utrecht, the Netherlands. \\ ${ }^{2}$ The Netherlands Organization for Health Research and Care Innovation, 2593 CE Den Haag, the \\ Netherlands.
}

Correspondence to: Ronald Batenburg, NIVEL, PO Box 1568, 3500 BN Utrecht, the Netherlands. Phone: +31 302729700 r.batenburg@nivel.nl ‘

\begin{abstract}
.
This paper addresses the question why the growth of community health centres in the Netherlands has strongly fluctuated, and has not become a dominant organization type in primary health care. This question is approached by describing four different periods and describe for each period the policy climate or conditions for community health centres. From this, the relationship between policy conditions and the strategic behaviour of community health centres is discussed.
\end{abstract}

\section{INTRODUCTION.}

In many high-income countries, primary care is regarded as key in sustaining accessible and affordable health care. ${ }^{1}$ As countries are facing a strong growth of an elderly population chronic illnesses are becoming the main burden of disease, which puts a strong pressure on primary care. This is increased by a shift from acute hospital care to ambulatory and preventive care at community level. At the same time, several developments have caused more cooperation between hospital and primary care services, as well as between different disciplines within primary care itself. Health community centres can be considered as a specific 'organizational format' to realize this multidisciplinary cooperation.

In the Netherlands, community health centres have been established rapidly in the 1970s and 1980s, but have remained remarkably small in number during the last decades. This runs against the expectation that due to the need for more cooperation within primary, and the changing preferences of health workers and health customers, community health centres in the Netherlands would have become a dominant type of organization in health care. There is an increase of general practitioner (GP) practices that have structural cooperative relations with other care providers, such as physiotherapists and midwives. ${ }^{2}$ Likewise there is a growing palette of community-oriented and disease-oriented ventures, including a growing number of practical initiatives with managerial services.

${ }^{3}$ Primary care is up-scaled by regulations that become more complex and therefore require more management. The introduction of a specific funding system for the care of chronically ill (diabetes, COPD) contributed to this. And last but not least, there is trend that care providers themselves increasingly want to work on a part-time basis, focusing on the care process itself and paid employment.

This paper addresses the question why, in historical perspective, the growth of community health centres in the Netherlands have strongly fluctuated, and has not become a dominant organization type in primary health care. This question is approached by distinguishing four different periods and describes for each period the policy climate or conditions for community health centres, and the related development of community health centres. 
After this, we discuss the relationship between policy conditions and the strategic behaviour of community health centres in the closing conclusion and discussion section.

\section{THE PATTERN OF COMMUNITY HEALTH CENTRE ESTABLISHMENTS IN THE NETHERLANDS, 1970- 2010.}

Since the 1960s, the first health organizations emerged as 'community health centres'. From the 1970s, the Netherlands Institute for Health Services research (NIVEL) started to register community health centres. A formal definition was applied as (translated): 'an institutional controlled partnership and common housing for integrated primary care, provided by at least two doctors, two nurses, a social worker, and possibly representatives from other disciplines in primary care'. The first measurement in 1974 counted 21 centres, which rapidly grew to 120 in $1983 .{ }^{4}$ During the 1980s this growth slowed down, stabilizing the number of community health centres to approximately $140 .{ }^{5}$ In 1992, NIVEL specifically surveyed all 161 community health centres at that time. ${ }^{6}$ From this survey it could be estimated that (at a national level) $3.4 \%$ of all GP practices were part of a community health centre, and $8.8 \%$ of all active general practitioners. It was also estimated that 1 million persons (then $7 \%$ of the Dutch population) was registered as a patient of a community health centre. This survey has been one of the last among the population of community health centres in the Netherlands.

In 1998, NIVEL stopped the central registration.

Since then, the most reliable source is the membership list of the Dutch Association for Organized Primary Care (LVG) that is published on their website. In 2011, this number is 197, if we count those members that have the Dutch word 'gezondheidscentrum' (community health centres) in their name, 'eerstelijns samenwerking' (primary care cooperation) or 'medisch centrum' (medical centre). The current definition of a community health centre that is published on the Dutch thesaurus (translated) is: 'a centre that offers GP care, social work and nursing under one roof; in some cases also includes physiotherapy, obstetrics, home care, pharmaceutical and dietary advice' (www.the sauruszorgenwelzijn.nl).

As from 1998 onwards no yearly registration of community health centres is in place, we used the membership list of the LVG in 2011 and retrieved the year of foundation for each centre, to estimate the trend in the Dutch population of community health centres over the longer period. This information could be retrieved for 112 centres through their websites and (year-end) report. The frequency distribution is presented in Figure 1.

Figure 1 shows a pattern which led to the demarcation of four periods. The first phase illustrates the first wave in the establishment of community health centres until 1984. After that year, a clear period of stabilization and low numbers of establishments per year occurred. A third period can then be marked between 2000 and 2006, a small second wave of community health centre establishment. We mark the year 2006 as a transition point, as from then on the wave seem to dropped again, with 2009 as a year of exception. It should be noted that many of the community health centres founded after 2000 are part of a larger holding, a trend that will be described in more detail later in this paper. Also, the community health centres founded after 1984 are typically located in the 'new district' areas in the Netherlands, build on new formally rural land.

Next, we will describe each of the four periods in more detail, with regard to their policy climate and other relevant conditions for community health centres.

\section{Period 1967-1984: optimism and expansion.}

Since the early 1970s, the Dutch government in its health policies strongly supported primary care as the cornerstone of its health system. In that decade, community health centres were seen as a preferred organizational form of modernized and integrated primary care. The Ministry of Health shows in several of its policy letters that community health centres are expected to provide an accessible point of contact for patients close to their homes. In addition, it was strongly believed that community health centres could deliver care in the most efficient and effectiveway,minimizing patient referral to secondary care, and providing treatment of patients with accurate information on prevention. In 1974, the first community health centres were publically funded by the Ministry of Health. The conditions for this funding changed during the 1970s and 1980s, but the principle remained the same, i.e. to support community health centres in their start-up phase to overcome the pre-investment costs and risks. As indicated before, during this period a lot of new housing districts were developed to compensate the housing shortage that emerged after the Second World War and increased during the 1960s. A good example is the foundation of community 
health centres in Almere in $1980 .{ }^{7}$ Community health centres were also founded in the larger cities such as Rotterdam, Amsterdam, Maastricht, Nijmegen, and Utrecht.

\section{Period 1985-2000: drawback and decline}

\section{[FIGURE 1].}

During the 1980s, a positive evaluation study were published showing that GPs in community health centres referred their patients less frequently to the specialized health care, controlling for case mix and other relevant conditions. ${ }^{4}$ It was also found that the length of stay per admission was lower decreasing costs of health care by reduced use of hospital services (ibid). Meanwhile, however, economic fallback and budget cutting reached the health care domain. First in 1987, the funding of community health centre foundation was restricted to a maximum of new centres. Then, by the health system reform initiated by a committee supervised by state secretary Simons a lot of political pressure emerged was to actually abolish the funding subsidy which was postponed just before the year $2000 .^{8}$ As a result, the growth of community health centres rapidly dropped to a minimum. Only some new centres were established, will some other consolidated or expanded as a chain or holding (Almere, Amsterdam, The Netherlands). The contrast of this trend is enlarged if noted that during the same period health care expenditure in the Netherlands constantly grew and so was the number of care providers, e.g. GPs.

\section{PERIOD 2001-2006: A SHORT UPTAKE.}

The relatively short period 2000-2006 is characterized by a short uptake in the foundation of new community health centres. This new wave had different drivers. One was the further consolidation and expansion of community health centres under holdings, as a result of mergers of strategic cooperation of particularly the larger centres in the Netherlands. In addition, health insurance companies initiated the foundation of community health centres, such as Menzis. This 'new player' obviously brought new dynamics in the sector. With regard to the policy climate for community health centres, a renewed ambition was launched. While budget pressure was still present, a breakthrough was the signing of the Intention Declaration for Enforcing Primary care in 2004 by the Ministry of Health, health insurers, care providers, patient organizations, and the LVG. New funding was mobilized to support regional collaboration between disciplines in primary care. At the same time, however, in 2006 the subsidy for community health centres foundation after two decades of discussion was finally phased out.

\section{PERIOD 2007-PRESENT: UNCERTAINTY AND OPPORTUNITIES.}

From 2006, until recently some consolidation of community health centres occurred, resulting in the foundation of a number of new centres.

Continuation of a second wave of new community health centres appears to be bound to happen, however. An important reason is the phasing-out and abolishment of the start-up subsidy by the government. At the same time, in 2006, the health care system in the Netherlands was reformed, introducing more market mechanisms and less central government control. An important shift was that health care insurers are put in a key position of the health care system, contracting optimal care for their customers through negotiation with care providers. As a consequence, primary care providers (including community health centres) were forced to negotiate and interact with different health insurers on amuch more intense basis. In the new playing field some health insurers are willing to support health community centres to expand or innovate, but the conditions and requirements for this support are largely under construction. While currently some health organizations explore the founding of new (community) health centres, alternative type of collaboration (care chains, networks, 'care groups', in particular for chronic diseases) also occur within primary care. This means that health community centres are actually in competition with other organizational forms.

\section{CONCLUSION AND DISCUSSION.}

From the analysis of four decades it has become clear that public governmental funding has played an important role in the foundation and consolidation of health community centres in the Netherlands. Many of the centres were founded in the 1960 and 1970, financially supported by the Dutch government. When the subsidy was under pressure during the 1980, the foundation of community health centres slowed down. 
Around the year 2000 a short 'revival' of community health centres emerged, but it also became clear that a clear second wave of community health centres foundation was bound to happen. Although the subsidy for community health centres was changed a number of times, it remained in place until 2006. Since that year, care insurers have become the main financial stakeholders for community health centres, creating a new level playing field. Although it might be too early to conclude so, it can notice that community health centres prefer to expand through consolidation and merges, instead of founding new independent centres. In addition, it can be notified that community health centres are not the only preferred organizational form in primary care, as many alternative forms are emerging.

It still remains an interesting question why community health centres have not become the dominant organization form in Dutch primary health care, and this premises was apparently adjourned during the 1990 - recalling that during this decade governmental subsidy was still available. It seems that the momentum for community health centres was lost at some point. It has always been a great risk and investment to found a new community health centre, especially because new housing demands long-term investments and hence external funding. This search for funding has become more and more complex over time, due to the new role of health insurers and the central government since 2006, but also due to banks and municipalities as new playing field partners. Until now, health insurers do not have a uniform policy in supporting community health centres, which make it difficult for primary care providers to negotiate with different stakeholders at different occasions. This extends the uncertainty community health centres deal with, in particular when new centres are to be founded.

This re-addresses the question as to whether the government should provide a stable funding base for community health centres that are starting from a 'green field' situation (i.e. a rural area). On the other hand, community health centres actually fit in the new wave of the market oriented health care system, and hence their foundation are to be seen as a business case that should excludes governmental influence. This has led to the paradox that despite the proven advantages of community health centres in terms of cost control and referrals, these centres are not or only partly stimulated by the government as they believe that these initiatives flourish more in market instead of public settings.

Since 2006, health care in the Netherlands ranks high on international benchmarks. A Commonwealth Fund study showed that the Netherlands outperforms other European countries and the USA on accessibility and quality of care. ${ }^{9}$ This is also visible in good accessible care in all regions, continuity of care by personal registration in general practices and stepped access to medical specialists. The same Commonwealth Fund study also showed that the level of patient-centred care in the Netherlands is relatively poor. In the autumn of 2004, the Ministry of Public Health, Welfare and Sports, and the parties in the field declared themselves in favour of a 'reinforcement of primary health care' as a common ambition.

Innovative parts of this are the local health situation and a coherent and adequate supply of facilities with special attention to prevention and the relationship between care and welfare. A potential weakness of the Dutch primary health care system remains the fragmentation of primary care practices across several disciplines, however. This enforces the risk of a lack of coordination and continuity in primary care provision. This weakness has been recognized by the Dutch government and policy makers for a long time. It remains an open question if community health centres will become the main organizational form to cope with these risks in the near future.

\section{REFERENCES.}

1. WHO. Health Report 2008: Primary Health Care - Now More Than Ever. Geneva, World Health Organisation 2008.

2. Hansen J. Monitor multidisciplinaire samenwerking in de eerste lijn (in Dutch). Utrecht: NIVEL, 2010.

3. Hopman EPC, Batenburg R, Bakker DH.

Organisatorische samenwerkingsverbanden binnen de eerste lijn - een verkennin (in Dutch). Utrecht: NIVEL; 2009.

4. Peters L, Wijkel D. Meerkosten en besparingen van gezondheidscentra (in Dutch). Med Contact, (39), January 20, 1984, p. 87-91.

5. Boerma WGW. Verminderde groei van het aantal gezondheidscentra (in Dutch). Tijdschrift voor Sociale Gezondheidszorg. 65(23), 1987, p. 728.

6. Hingstman L, Hoekstra J. Gezondheidscentra peiling 1997: gezondheidscentra in Nederland op gemeenteniveau (in Dutch). Utrecht: NIVEL; 1998. 
Batenburg, R., Eyck, A. The growth and decline of health community centres in the Netherlands: a macro 7 historical analysis. Journal of Management and Marketing in Healthcare: 2011, 4(4), 242-246

7. Sixma HJM. 'New land, new town, new health care system: primary care based health care', 'planning in a modern, industrialized society; a casestudy evaluating the', 'health care demonstration project in the new Dutch town of Almere'. Utrecht: NIVEL; 1997.

8. Schäfer W, Kroneman M, Boerma W, Berg M van den, Westert G, Devillé W, Ginneken E van. The Netherlands: health system review. Kopenhagen: WHO; 2010.

9. Davis K, Schoen C, Stremikis K. Mirror, Mirror on the Wall. How the Performance of the U.S. Health Care System Compares Internationally. The Commonwealth Fund. 2010.

\section{AUTHOR INFORMATION.}

Ronald Batenburg is program coordinator health professions and labour markets at NIVEL, the Netherlands Institute of Health Services Research.

Arthur Eyck is program director Public Health and Integrated Primary Care at ZonMw, the Netherlands

Organization for Health Research and Care Innovation.

\section{FIGURE}

Figure 1: Numbers of Dutch community health centres by year of establishment, marking the four policy periods $(n=112)$.

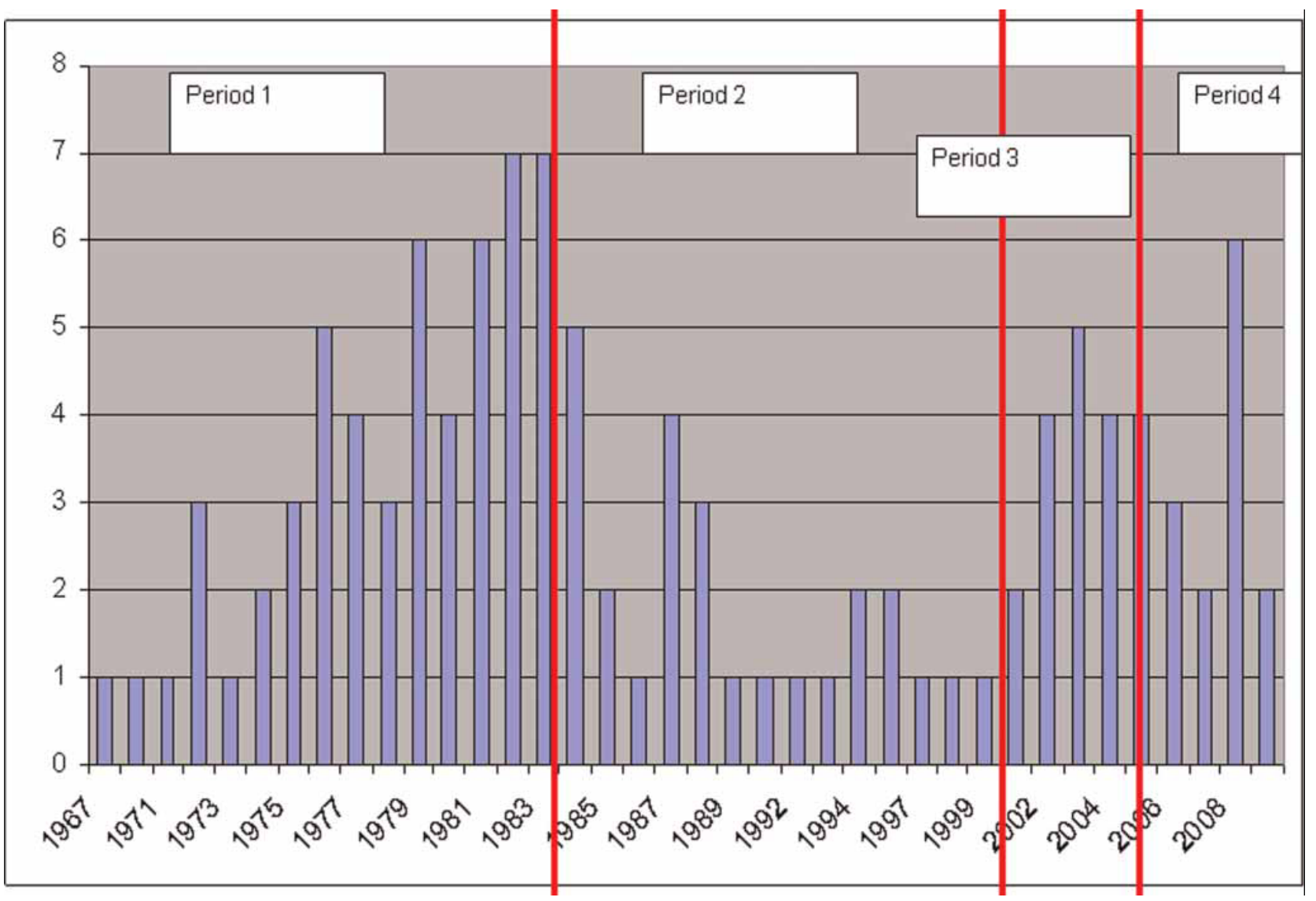

